\section{Reply to M.J. Molina-Garrido et al}

We would like to thank Molina-Garrido and Guillén-Ponce ${ }^{1}$ for their comments on our article, and appreciate this opportunity to clarify some of the points they discussed.

The vulnerable elders survey-13 (VES-13) is a geriatric instrument that has been validated as a means of indentifying elderly people with functional decline. ${ }^{2}$ Patients are considered vulnerable if their score is 3 or higher, and an age older than 85 years is considered a criterion of vulnerability by itself. These criteria were established in a cohort of nononcologic elderly patients.

The aim of our clinical trial was to compare the accuracy of VES-13 with the Comprehensive Geriatric Assessment (CGA) in detecting disabilities in elderly patients with cancer. We made an intrapatient analysis, and both scales were administered to every patient, thus reducing the possible biases arising from the type of population. Our patient series is larger than those of previously published studies, and unlike a previous study of patients with prostate cancer ${ }^{3}$ in which the comparison involved the CGA as a whole (including the evaluation of cognitive and depressive status, which are not assessed by the VES-13 items), we only compared homogeneous items (ie, we only analyzed CGA functional status scores corrected for an age older than 85 years or younger than 85 years. The conclusions of our study underline the usefulness and accuracy of VES-13 when diagnosing impaired functional status in everyday clinical practice.

The National Comprehensive Cancer Network and the International Society of Geriatric Oncology guidelines ${ }^{3 a}$ recommend assessing elderly patients with cancer by using any form of geriatric evaluation regardless of the length of the instrument or how long it takes to complete. There is no answer to the question as to which instrument is the best. We believe that research should concentrate on identifying new screening tools for assessing the impact of geriatric impairments on oncologic outcomes (such as survival or toxicity) rather than on finding new cutoff points for classic geriatric scales, given that this should promote the wider use of geriatric assessments in oncologic clinics. Multicenter and international validations are the most appropriate methodologic means of avoiding selection biases.
The Groningen fragility index ${ }^{4}$ or Barber's test ${ }^{5}$ do not seem to be suitable, and the VES-13 itself is far from an ideal screening tool, because it evaluates only one CGA dimension and is not rapid even when self-administered. G-8 is a promising abbreviated screening instrument that has been validated by French geriatric oncology centers, and given that it will be prospectively tested in a European Organisation for Research and Treatment of Cancer clinical trial, we presume that it will soon be possible to draw more precise conclusions.

Many geriatric assessment instruments have been published, none of which can be considered the best or most accurate. Clinicians need to be aware that any modified CGA may miss some clinical information; modified versions should not completely replace the original.

\section{Andrea Luciani and Paolo Foa \\ San Paolo Hospital; and University of Milan, Milan, Italy}

\section{AUTHORS' DISCLOSURES OF POTENTIAL CONFLICTS OF INTEREST}

The author(s) indicated no potential conflicts of interest.

\section{REFERENCES}

1. Molina-Garrido MJ, Guillén-Ponce C: Overvaluation of the vulnerable elders survey-13 as a screening tool for vulnerability. J Clin Oncol doi: 10.1200/ JCO.2011.36.3911

2. Saliba D, Elliott M, Rubenstein LZ, et al: The vulnerable elders survey: A tool for identifying vulnerable older people in the community. J Am Geriatr Soc 49:1691-1699, 2001

3. Mohile SG, Bylow K, Dale W, et al: A pilot study of the vulnerable elders survey-13 compared with the comprehensive geriatric assessment for identifying disability in older patients with prostate cancer who receive androgen ablation. Cancer 109:802-810, 2007

3a. Extermann M, Aapro M, Bernabei R, et al: Use of comprehensive geriatric assessment in older cancer patients: Recommendations from the task force on CGA of the International Society of Geriatric Oncology (SIOG). Crit Rev Oncol Hematol 55:241-252, 2005

4. Kellen E, Bulens P, Deckx L, et al: Identifying an accurate pre-screening tool in geriatric oncology. Crit Rev Oncol Hematol 75:243-248, 2010

5. Molina-Garrido MJ, Guillen-Ponce C: Comparison of two frailty screening tools in older women with early breast cancer. Crit Rev Oncol Hematol 79:51-64, 2010

DOI: 10.1200/JCO.2011.36.5197; published online ahead of print at www.jco.org on July 11, 2011

\title{
Acknowledgment
}

We thank all the coauthors of our article for their contributions. 